\title{
Effect of Adsorbed Water and Temperature on the Universal Power Law Behavior of Lepidocrocite-Type Alkali Titanate Ceramics
}

\author{
Saichon Sriphan, ${ }^{a}$ Phieraya Pulphol, ${ }^{b}$ Thitirat Charoonsuk, ${ }^{c}$ Tosapol Maluangnont, ${ }^{b *}$ \\ and Naratip Vittayakorn ${ }^{d}$
}

${ }^{a}$ Faculty of Science, Energy and Environment, King Mongkut's University of Technology North Bangkok, Rayong 21120, Thailand

${ }^{b}$ Electroceramics Research Laboratory, College of Materials Innovation and Technology, King Mongkut's Institute of Technology Ladkrabang, Bangkok 10520, Thailand

${ }^{c}$ Department of Materials Science, Faculty of Science, Srinakharinwirot University, Bangkok 10110, Thailand

${ }^{d}$ Advanced Materials Research Unit, Department of Chemistry, School of Science, King Mongkut's Institute of Technology Ladkrabang, Bangkok 10520, Thailand

*Corresponding author: tosapol.ma@,kmitl.ac.th 


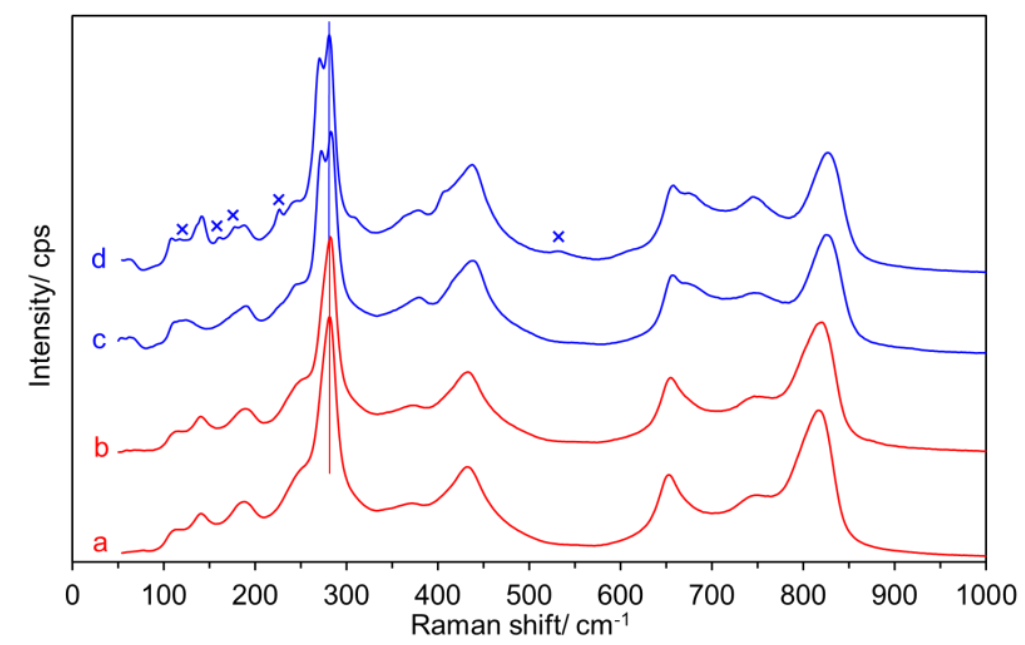

Figure S1 Raman spectra of: (a) as made $\mathrm{K}_{0.8} \mathrm{Zn}_{0.4} \mathrm{Ti}_{1.6} \mathrm{O}_{4}$, (b) $1100{ }^{\circ} \mathrm{C}$-sintered $\mathrm{K}_{0.8} \mathrm{Zn}_{0.4} \mathrm{Ti}_{1.6} \mathrm{O}_{4}$, (c) as made $\mathrm{Cs}_{0.7} \mathrm{Zn}_{0.35} \mathrm{Ti}_{1.65} \mathrm{O}_{4}$, and (d) $1100{ }^{\circ} \mathrm{C}$-sintered $\mathrm{Cs}_{0.7} \mathrm{Zn}_{0.35} \mathrm{Ti}_{1.65} \mathrm{O}_{4}$. (The Raman spectra were recorded using a DXR Smart Raman (Thermoscientific) at the laser wavelength of $532 \mathrm{~nm}$ and the laser power of $5 \mathrm{~mW}$.)

The Raman spectra in Figure S1 show bands characteristics of the lepidocrocite-type alkali titanate. ${ }^{1,2,3}$ There are no notable differences between as made vs $1100{ }^{\circ} \mathrm{C}$-sintered $\mathrm{K}_{0.8} \mathrm{Zn}_{0.4} \mathrm{Ti}_{1.6} \mathrm{O}_{4}$ (Figure $\mathrm{S} 1 \mathrm{a}, \mathrm{b}$ ) regarding peak positions, peak widths, or the presence of additional peaks. The impurity phase(s) detected by XRD ( $\circ$ in Figure 1ai in the manuscript) has low intensity and is visible after magnification by a factor of 4. Apparently, its content is too small to be observed in the Raman spectrum.

On the other hand, the $1100{ }^{\circ} \mathrm{C}$-sintered $\mathrm{Cs}_{0.7} \mathrm{Zn}_{0.35} \mathrm{Ti}_{1.65} \mathrm{O}_{4}$ shows additional, smallintensity bands ( $\times$ in Figure S1d) compared to the as made $\mathrm{Cs}_{0.7} \mathrm{Zn}_{0.35} \mathrm{Ti}_{1.65} \mathrm{O}_{4}$ (Figure S1c). ${ }^{3}$ These weak bands are at 142, 161, 178, 227, 309 and $536 \mathrm{~cm}^{-1}$. They correspond to the single impurity peak at $2 \theta \sim 42.6^{\circ}(2.12 \AA)$ ( $\times$ in Figure 1aii in the manuscript). As reported in our recent work, ${ }^{3}$ this was similarly observed in $1100{ }^{\circ} \mathrm{C}$-sintered $\mathrm{Cs}_{0.7} \mathrm{Ni}_{0.35} \mathrm{Ti}_{1.65} \mathrm{O}_{4}$ (i.e., the intralayer $\mathrm{Zn}$ is replaced by $\mathrm{Ni}$ ). Considering that different samples shared the same impurity peak, it is proposed that the impurity phase(s) could be some $\mathrm{Ti}_{\mathrm{x}} \mathrm{O}_{\mathrm{y}}$ or Cs-Ti-O but not the $\mathrm{Zn}_{\mathrm{x}} \mathrm{O}_{\mathrm{y}}$.

The content of the impurity phase(s) in $\mathrm{Cs}_{0.6} \mathrm{~K}_{0.1} \mathrm{Zn}_{0.35} \mathrm{Ti}_{1.65} \mathrm{O}_{4}(\boldsymbol{\varpi}$ in Figure 1aiii in the manuscript) is more extensive. So, it is difficult to interpret the Raman spectrum (not shown). 


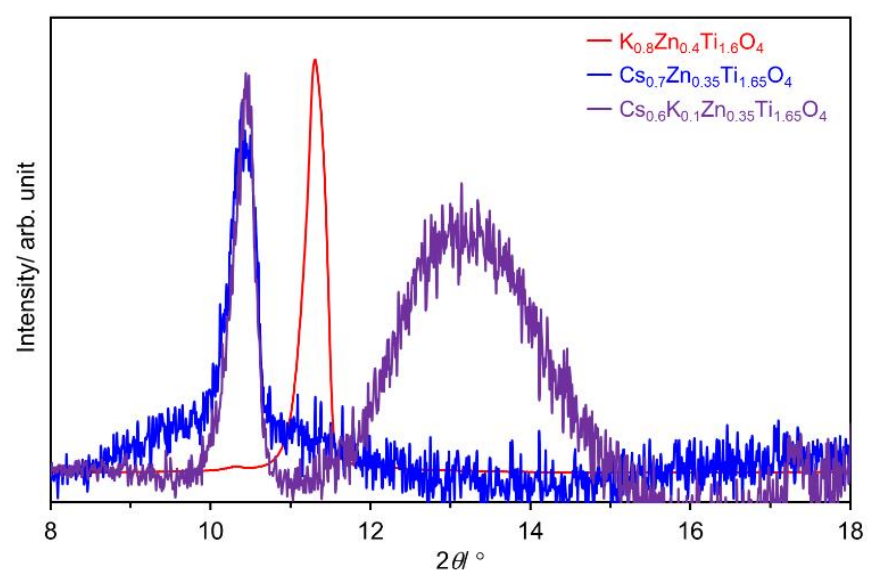

Figure S2 The zoom-in to the (020) reflections in the XRD patterns, which are normalized such that they have approximately the same peak intensity.

Quite unexpectedly, the peak width of $\mathrm{Cs}_{0.6} \mathrm{~K}_{0.1} \mathrm{Zn}_{0.35} \mathrm{Ti}_{1.65} \mathrm{O}_{4}$ (purple) is very close to that of $\mathrm{Cs}_{0.7} \mathrm{Zn}_{0.35} \mathrm{Ti}_{1.65} \mathrm{O}_{4}$ (blue) despite of having a very distinct halo at $2 \theta \sim 13^{\circ}$. In combination with the SEM observations, it is likely that the halo is a contribution from the irregularly shaped particles on the top surface. 


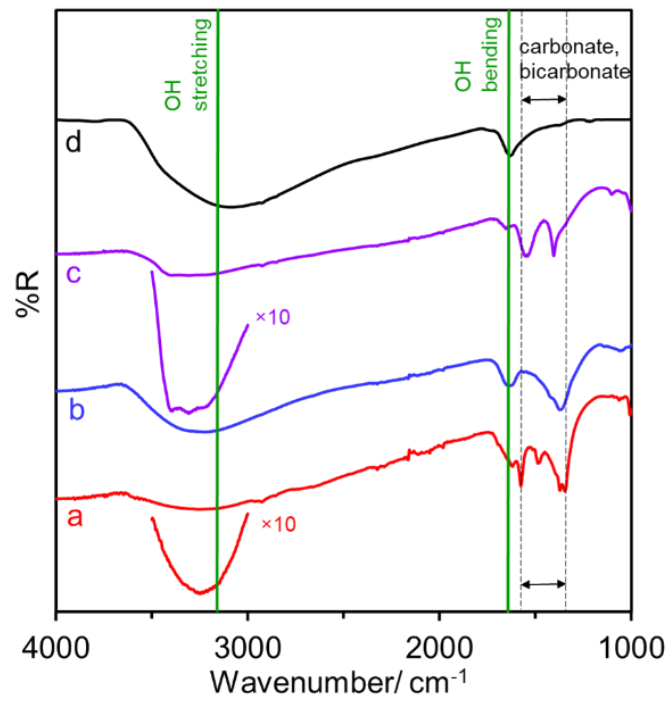

Figure S3 IR spectra of: (a) as made $\mathrm{K}_{0.8} \mathrm{Zn}_{0.4} \mathrm{Ti}_{1.6} \mathrm{O}_{4}$, (b) as made $\mathrm{Cs}_{0.7} \mathrm{Zn}_{0.35} \mathrm{Ti}_{1.65} \mathrm{O}_{4}$, (c) as made $\mathrm{Cs}_{0.6} \mathrm{~K}_{0.1} \mathrm{Zn}_{0.35} \mathrm{Ti}_{1.65} \mathrm{O}_{4}$, and (d) $\mathrm{H}_{1.6} \mathrm{Ti}_{1.6} \mathrm{O}_{4} \cdot \mathrm{H}_{2} \mathrm{O}$. (The IR spectra were recorded in the attenuated total reflectance (ATR) mode using a PerkinElmer, Spectrum 2 instrument with a resolution of $4 \mathrm{~cm}^{-1}$.)

The IR spectra in Figure S3 show signals indicative of two species. The peaks at $1345-1575 \mathrm{~cm}^{-1}$ are due to surface carbonate and bicarbonate, ${ }^{4,5}$ which were previously confirmed by XPS. ${ }^{5}$ On the other hand, the relatively sharp peak at $1633 \mathrm{~cm}^{-1}$ and the broad one at $3000-3500 \mathrm{~cm}^{-1}$ are ascribed to, respectively, $\mathrm{OH}$ bending and $\mathrm{OH}$ stretching. These two peaks are the strong evidence supporting the presence of water in our samples. This assignment is further supported by the comparison with $\mathrm{H}_{1.6} \mathrm{Ti}_{1.6} \mathrm{O}_{4} \cdot \mathrm{H}_{2} \mathrm{O}$ (Figure $\mathrm{S} 2 \mathrm{~d}$ ) containing intercalated water, which was prepared from acid exchange and zinc leaching ${ }^{4,6}$ of $\mathrm{K}_{0.8} \mathrm{Zn}_{0.4} \mathrm{Ti}_{1.6} \mathrm{O}_{4}$. 

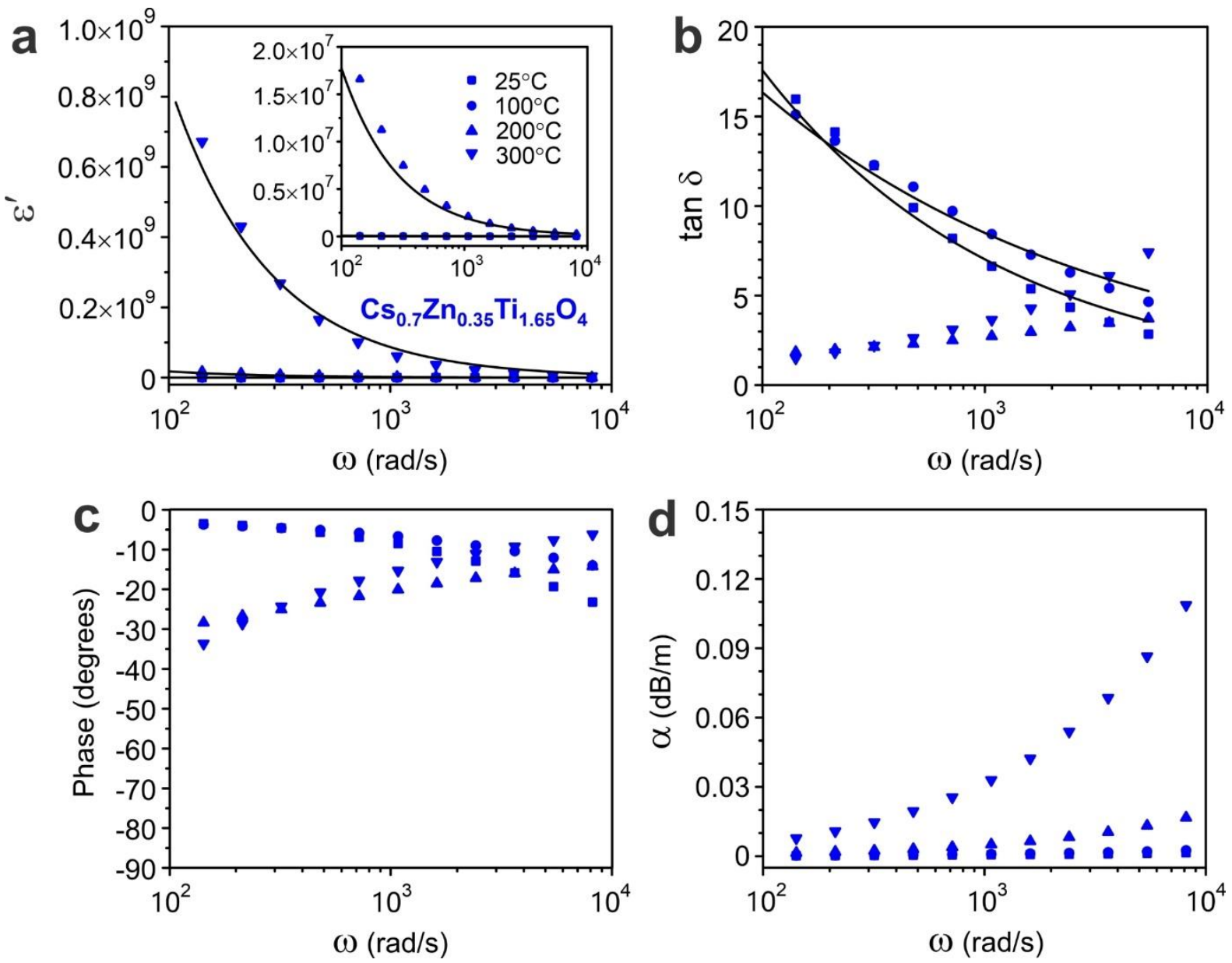

Figure S4 Frequency-dependent dielectric properties and some other parameters derived therefrom of a pretreated $\mathrm{Cs}_{0.7} \mathrm{Zn}_{0.35} \mathrm{Ti}_{1.65} \mathrm{O}_{4}$ pellet at different temperatures: (a) dielectric permittivity $\varepsilon^{\prime}$, (b) loss tangent $\tan \delta$, (c) phase $\theta$, and (d) attenuation coefficient $\alpha$. The values were recorded (or calculated from the data) upon cooling from $400{ }^{\circ} \mathrm{C}$ to the target temperatures. The lines in (a) are the fits by eq (1), while the lines in (b) are the fits by eq (2) in the manuscript. 

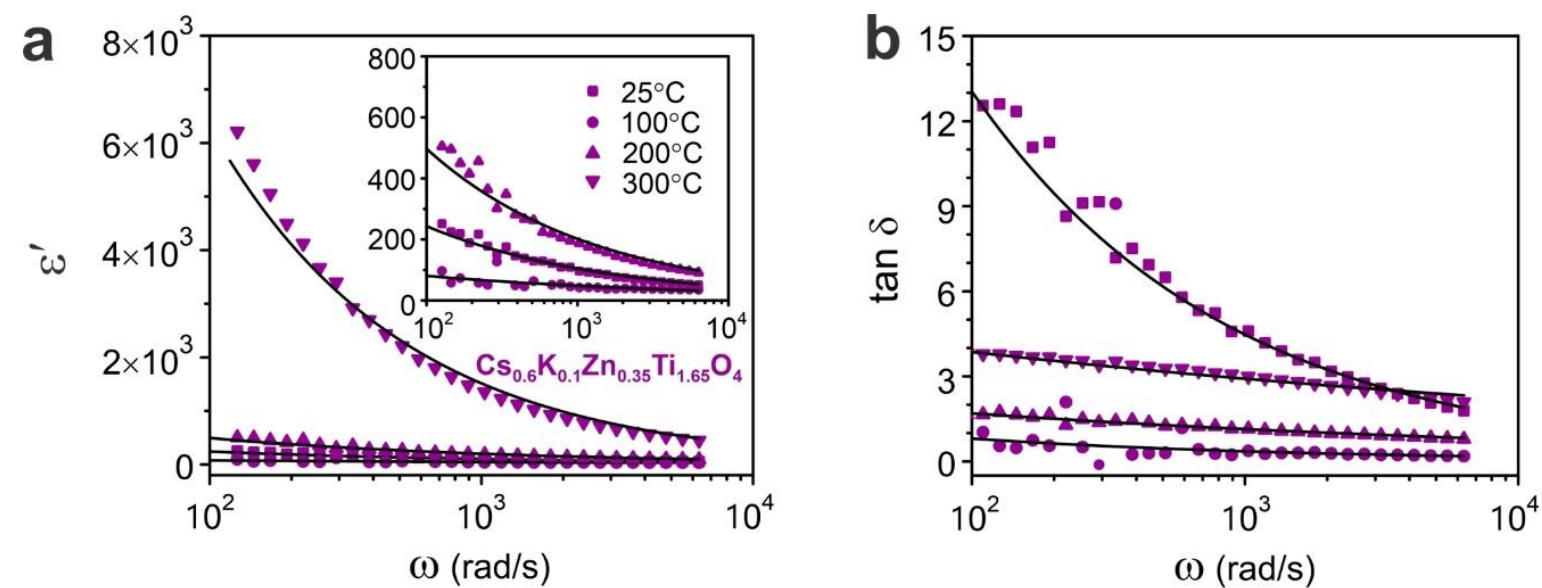

$\omega(\mathrm{rad} / \mathrm{s})$
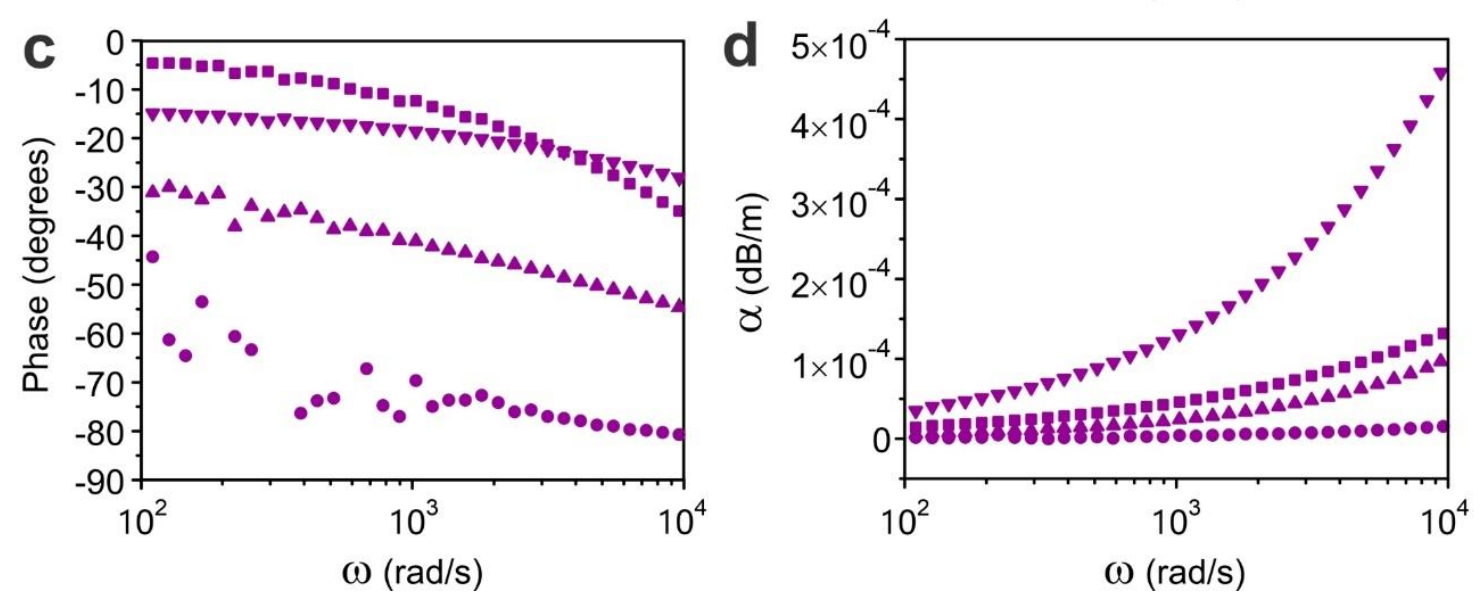

Figure S5 Frequency-dependent dielectric properties and some other parameters derived therefrom of a pretreated $\mathrm{Cs}_{0.6} \mathrm{~K}_{0.1} \mathrm{Zn}_{0.35} \mathrm{Ti}_{1.65} \mathrm{O}_{4}$ pellet at different temperatures: (a) dielectric permittivity $\varepsilon^{\prime}$, (b) loss tangent $\tan \delta$, (c) phase $\theta$, and (d) attenuation coefficient $\alpha$. The values were recorded (or calculated from the data) upon cooling from $400{ }^{\circ} \mathrm{C}$ to the target temperatures. The lines in (a) are the fits by eq (1), while the lines in (b) are the fits by eq (2) in the manuscript. 

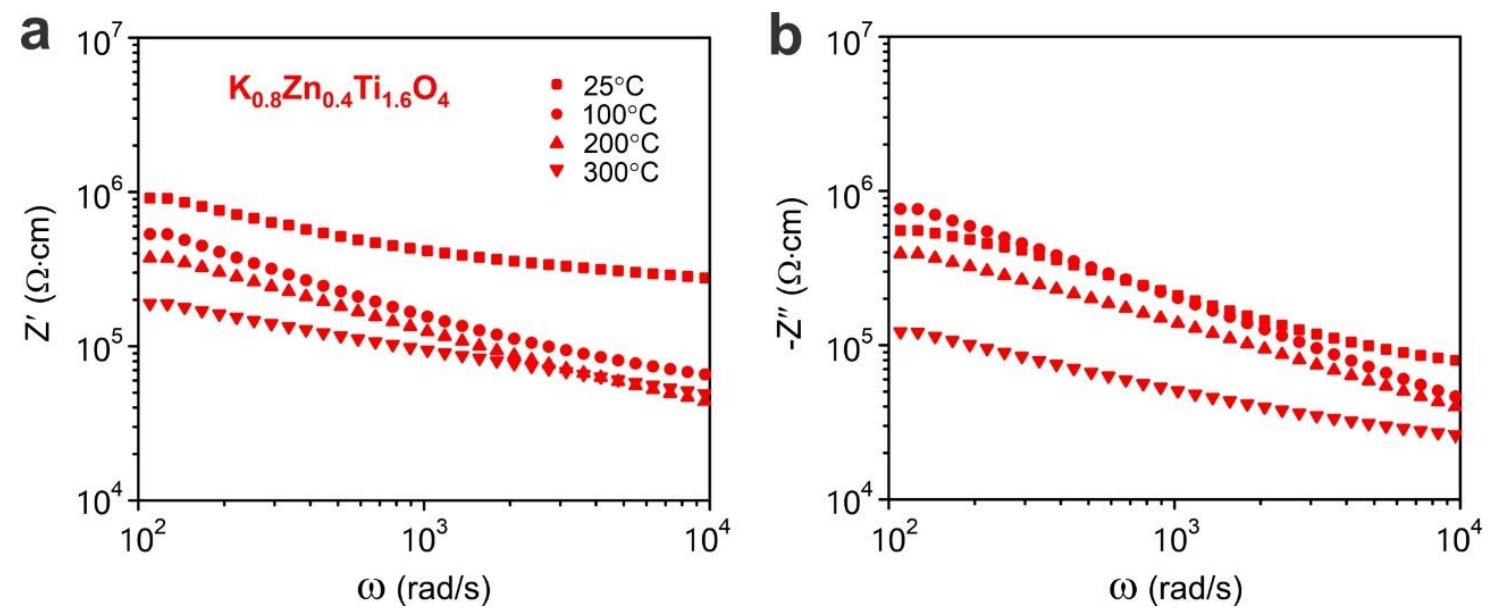

Figure S6 Frequency-dependent impedance spectra of a pretreated $\mathrm{K}_{0.8} \mathrm{Zn}_{0.4} \mathrm{Ti}_{1.6} \mathrm{O}_{4}$ pellet at different temperatures: (a) real, and (b) imaginary part. Note the anomaly at $100{ }^{\circ} \mathrm{C}$ which is observed in (b), where $-Z^{\prime \prime}\left(100^{\circ} \mathrm{C}\right)>-Z^{\prime \prime}\left(25^{\circ} \mathrm{C}\right)>-Z^{\prime \prime}\left(200^{\circ} \mathrm{C}\right)>-Z^{\prime \prime}\left(300^{\circ} \mathrm{C}\right)$. Meanwhile, such anomaly is not detected in $Z^{\prime}$, giving the expected trend: $Z^{\prime}\left(25^{\circ} \mathrm{C}\right)>Z^{\prime}\left(100^{\circ} \mathrm{C}\right)>$ $Z^{\prime}\left(200{ }^{\circ} \mathrm{C}\right)>Z^{\prime}\left(300^{\circ} \mathrm{C}\right)$. 


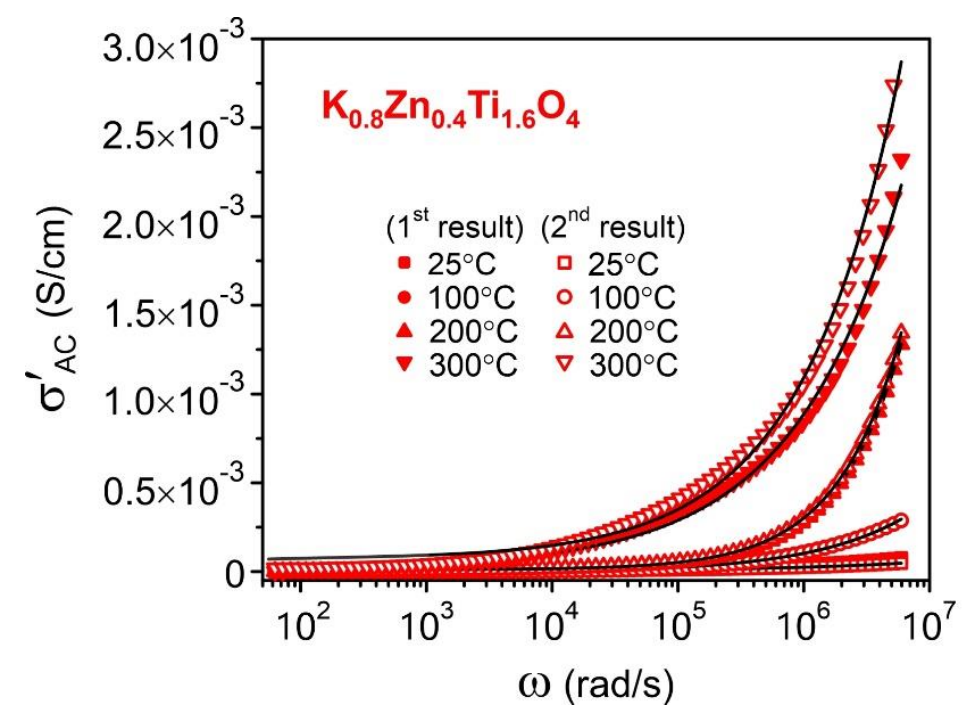

Figure S7 Reproducibility of the frequency-dependent AC conductivity measurements on a pretreated $\mathrm{K}_{0.8} \mathrm{Zn}_{0.4} \mathrm{Ti}_{1.6} \mathrm{O}_{4}$ pellet at different temperatures, conducted several months apart. The values were recorded upon cooling from $400{ }^{\circ} \mathrm{C}$ to the target temperatures. The lines are the fit to the equation $\sigma_{\mathrm{AC}}(\omega)=\sigma_{\mathrm{DC}}+A \omega^{s}$.

Table S1 Summary of fitting parameters of the angular frequency-dependent total conductivity $\sigma_{\mathrm{AC}}(\omega)=\sigma_{\mathrm{DC}}+A \omega^{s}$ for a pretreated $\mathrm{K}_{0.8} \mathrm{Zn}_{0.4} \mathrm{Ti}_{1.6} \mathrm{O}_{4}$ pellet, obtained from experiments several months apart. The number in parenthesis indicates the standard deviation of the last digit.

\begin{tabular}{|c|c|c|c|c|}
\hline$T /{ }^{\circ} \mathrm{C}$ & Parameter & $1 \mathrm{st}$ & 2nd & Average (standard deviation) \\
\hline 25 & $\sigma_{\mathrm{DC}}$ & $1.68 \times 10^{-7}$ & $5.62 \times 10^{-7}$ & $4(3) \times 10^{-7}$ \\
& $A$ & $1.75 \times 10^{-7}$ & $1.53 \times 10^{-7}$ & $1.6(2) \times 10^{-7}$ \\
& $S$ & 0.359 & 0.367 & $0.363(6)$ \\
\hline 100 & $\sigma_{\mathrm{DC}}$ & $-2.98 \times 10^{-6}$ & $-2.85 \times 10^{-6}$ & $-2.91(9) \times 10^{-6}$ \\
& $A$ & $4.63 \times 10^{-8}$ & $3.15 \times 10^{-8}$ & $4(1) \times 10^{-8}$ \\
& $S$ & 0.562 & 0.587 & $0.58(2)$ \\
\hline 200 & $\sigma_{\mathrm{DC}}$ & $7.81 \times 10^{-6}$ & $7.61 \times 10^{-6}$ & $7.7(1) \times 10^{-6}$ \\
& $A$ & $2.17 \times 10^{-9}$ & $2.48 \times 10^{-9}$ & $2.3(2) \times 10^{-9}$ \\
& $S$ & 0.851 & 0.846 & $0.849(4)$ \\
\hline 300 & $\sigma_{\mathrm{DC}}$ & $4.21 \times 10^{-5}$ & $3.93 \times 10^{-5}$ & $4.1(2) \times 10^{-5}$ \\
& $A$ & $4.46 \times 10^{-7}$ & $6.02 \times 10^{-7}$ & $5(1) \times 10^{-7}$ \\
& $S$ & 0.556 & 0.541 & $0.55(1)$ \\
\hline
\end{tabular}




\section{Additional references}

1. Dong, X.; Osada, M.; Ueda, H.; Ebina, Y.; Kotani, Y.; Ono, K.; S, U.; Kobayashi, K.; Takada, K.; Sasaki, T., Synthesis of Mn-substituted titania nanosheets and ferromagnetic thin films with controlled doping. Chem. Mater. 2009, 21, 4366-4373; Song, H.; Sjåstad, A. O.; Vistad, Ø. B.; Gao, T.; Norby, P., Preparation of $\mathrm{Nb}$-substituted titanates by a novel sol-gel assisted solid state reaction. Inorg. Chem. 2009, 48, 6952-6959.

2. Gao, T.; Fjellvåg, H.; Norby, P., Defect chemistry of a zinc-doped lepidocrocite titanate $\mathrm{Cs}_{\mathrm{x}} \mathrm{Ti}_{2-}$ $\mathrm{x} / 2 \mathrm{Zn}_{\mathrm{x} / 2} \mathrm{O}_{4}(\mathrm{x}=0.7)$ and its protonic form. Chem. Mater. 2009, 21, 3503-3513.

3. Charoonsuk, T.; Sriphan, S.; Pulphol, P.; Vittayakorn, W.; Vittayakorn, N.; Maluangnont, T., AC conductivity and dielectric properties of lepidocrocite-type alkali titanate tunable by interlayer cation and intralayer metal. Inorg. Chem. 2020, 59, 15813-15823.

4. Maluangnont, T.; Arsa, P.; Limsakul, K.; Juntarachairot, S.; Sangsan, S.; Gotoh, K.; Sooknoi, T., Surface and interlayer base-characters in lepidocrocite titanate: the adsorption and intercalation of fatty acid. $J$. Solid State Chem. 2016, 238, 175-181.

5. Maluangnont, T.; Chanlek, N.; Suksawad, T.; Tonket, N.; Saikhamdee, P.; Sukkha, U.; Vittayakorn, N., Beyond soft chemistry - bulk and surface modifications of polycrystalline lepidocrocite titanate induced by post-synthesis thermal treatment. Dalton Trans. 2017, 46, 14277-14285.

6. Petpiroon, N.; Bhummaphan, N.; Soonnarong, R.; Chantarawong, W.; Maluangnont, T.; Pongrakhananon, V.; Chanvorachote, $\mathrm{P} ., \mathrm{Ti}_{0.8} \mathrm{O}_{2}$ nanosheets inhibit lung cancer stem cells by inducing production of superoxide anion. Mol. Pharmacol. 2019, 95, 418-432. 